\title{
Screening for Osteoporosis - Making an Informed Choice of DXA or Calcaneal QUS
}

\author{
Varsha Narayanan* \\ Health and Pharmaceutical Consultant, Dr Varsha's Health Solutions, Andheri west, Mumbai India
}

*Corresponding Author: Varsha Narayanan, Health and Pharmaceutical Consultant, Dr Varsha's Health Solutions, Andheri west, Mumbai India. Email: drvarsha@ rediffmail.com

\begin{abstract}
Osteoporosis is characterized by a reduction in bone mass or bone mineral density and an increase in fracture risk. As it runs a silent course before presenting with a fracture, the importance of screening especially of risk groups for timely diagnosis and treatment, cannot be overemphasized. Often in developing countries, where access to labs and devices like DXA may be limited, onsite high-volume screening can contribute significantly in diagnosing Osteoporosis cases and contribute towards reduction in morbidity and economic burden due to development offractures. Though DXA is the gold standard for Osteoporosis diagnosis, recently calcaneal quantitative ultrasound is emerging as a convenient, portable, low cost and radiation free device for in-clinic or onsite screening. Therefore, the differences in parameter interpretation and evaluation, along with relative advantages and disadvantages of using calcaneal QUS over DXA should be well understood before making an informed choice.
\end{abstract}

Keywords: DXA, DEXA, QUS, Osteoporosis, T score, BMD, Fracture

\section{INTRODUCTION}

Osteoporosis is a disease characterized by low bone mass (bone mineral density- BMD), decreased quality of bone tissue, and increased risk of fracture. [1] The loss in bone density usually continues silently over many years and a fracture may often be the first clinical manifestation usually of advanced disease by that time.

The common Osteoporotic fractures sites include the hip, spine, wrist, and shoulder. [1, 2] Osteopenia refers to decreased bone mineral density (BMD) as compared to normal peak density, but not low enough to significantly increase fracture risk and be considered as Osteoporosis, however it is a risk factor for Osteoporosis. [1] A single cause of Osteoporosis is not established therefore risk factor identification often helps in selecting screening groups to facilitate timely diagnosis. (Table 1). [3-12]

Over 200 million people worldwide, and approximately $30 \%$ of all postmenopausal women have Osteoporosis in the United States and in Europe. [13] In India more than 50 million people are either osteoporotic (T-score lower than-2.5) or have low bone mass (T-score between-1.0 and-2.5), and studies indicate that Osteoporosis and Osteopenia or low bone mass may occur at a relatively younger age in Indian population. [14] Screening has an important place in early diagnosis, care and treatment of Osteoporosis.

However, for mass screening or camps, cost and portability of equipment are realistic challenges and limitations. Though Dual-energy X-ray Absorptiometry (DXA or DEXA) remains the gold standard of diagnosis of Osteoporosis, the calcaneal Quantitative Ultrasound (QUS) has been increasingly used in screening camps due to it lower cost, easy transportation and convenience. Therefore, it becomes pertinent to understand how the calcaneal ultrasound compares to the standard DEXA, and what should be its rational and scientific place for measuring bone mineral density (BMD) for the screening and diagnosis of Osteopenia and Osteoporosis. 
Table1. Risk factor identification for Osteoporosis screening

\begin{tabular}{|c|c|c|}
\hline & Risk & Details \\
\hline 1 & Age[3] & $\begin{array}{l}\text { - } \quad 90 \% \text { hip fractures occur in people aged } \geq 50 \text { years. (independent risk factor) } \\
\text { - } \quad \text { Bone mineral density reduces with age. }\end{array}$ \\
\hline 2 & Female gender[4] & $\begin{array}{l}\text { - Post-menopausal women are more susceptible to bone loss than men due to reduced } \\
\text { estrogen hormone which is important in bone formation. } \\
\text { - Women are more likely to sustain an osteoporotic fracture than men with a } 40-50 \% \\
\text { lifetime risk in women, compared to } 13-22 \% \text { in men } \\
\text { - Peak bone mass reduced by late menarche. } \\
\text { - Premature menopause, especially before the age of } 45 \text {, is a strong determinant of bone } \\
\text { loss and increased risk of fracture [1] }\end{array}$ \\
\hline 3 & Ethnicity [5] & $\begin{array}{l}\text { - Osteoporosis is more common in Caucasian and Asian populations } \\
\text { - Lower incidence of Osteoporosis and hip fractures in black than in white people }\end{array}$ \\
\hline 4 & Family history[6] & $\begin{array}{l}\text { - Parental history of fracture (especially hip fracture) is associated with increased risk } \\
\text { of fracture (independent of BMD) }\end{array}$ \\
\hline 5 & $\begin{array}{l}\text { Past fracture } \\
\text { history[7] }\end{array}$ & $\begin{array}{l}\text { A previous fracture increases the risk of any fracture by } 86 \%, \\
\text { - } \quad \text { Double risk (1.86 times) of a second fracture }\end{array}$ \\
\hline 6 & $\begin{array}{l}\text { Systemic } \\
\text { comorbidities and } \\
\text { conditions }[8]\end{array}$ & $\begin{array}{l}\text { - Some systemic conditions constitute secondary risk factors that directly or indirectly } \\
\text { affect bone remodeling, mobility and balance, and increased risk of falling and } \\
\text { sustaining a fracture } \\
\text { Like Asthma, Crohn's or celiac disease, Rheumatoid arthritis, Hematological } \\
\text { disorders or Malignancies, Hypogonadal states, Endocrine disorders like Cushing's } \\
\text { syndrome, Hyperparathyroidism, Diabetes and Chronic Renal Failure. }\end{array}$ \\
\hline 7 & Drugs[9] & $\begin{array}{l}\text { - Some drugs directly weaken bone or increase fracture risk due to fall or trauma. } \\
\text { - Like Corticosteroids, Immunosuppressant (calcineurin inhibitors), L-Thyroxine, } \\
\text { Progesterone treatment, Aromatase inhibitors, Certain Antipsychotics, Antiepileptics, } \\
\text { Lithium, Methotrexate, Heparin, Antacids and Proton Pump Inhibitors }\end{array}$ \\
\hline 8 & Smoking $[10,11]$ & $\begin{array}{l}\text { - Associated with lower BMD, reduced body weight, earlier menopause, increased } \\
\text { metabolic breakdown of exogenous estrogen in women. } \\
\text { BMD } 2 \% \text { lower in smokers than in non-smokers for each } 10 \text {-year increase in age }(6 \% \\
\text { at age } 80 \text { years) } \\
\text { - Cigarette smoking is independent risk factor for hip fracture }\end{array}$ \\
\hline 9 & $\begin{array}{l}\text { Physical } \\
\text { Inactivity[12] }\end{array}$ & 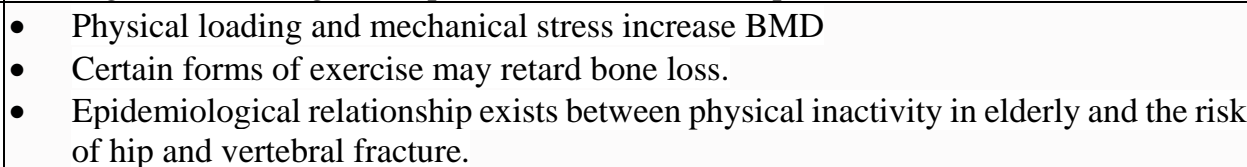 \\
\hline
\end{tabular}

\section{SCREENING AND DIAGNOSING OSTEOPOROSIS - CALCANEAL QUS OR DXA}

\section{Dual-energy X-ray absorptiometry}

(DXA, previously DEXA) measures bone mineral density (BMD). Two X-ray beams, with different energy levels, are aimed at the patient's bones (hip and lumbar spine) and the bone mineral density (BMD) is determined from the absorption of each beam by bone after soft tissue absorption is subtracted.[15] Dualenergy X-ray absorptiometry is the most and thoroughly studied bone density measurement technology and is the gold standard for measuring BMD and diagnosing Osteoporosis.

Bone densities are expressed as $\mathrm{T}$ score or $\mathrm{Z}$ score. [16] $\mathrm{T}$ score expresses $\mathrm{BMD}$ in comparison to a young adult of the same gender with peak BMD. A normal T score is $\geq-1.0$, low bone density (Osteopenia) is between -1.0 and 2.5, and Osteoporosis is $\leq-2.5$. Z score expresses $\mathrm{BMD}$ in comparison to the average BMD of a male or female of their age and weight. Severe or established Osteoporosis refers to a T-score more than -2.5 standard deviations below the young adult female reference mean in the presence of one or more fragility fractures.

Quantitative ultrasound (QUS) has recently emerged as a convenient and popular screening tool for Osteoporosis, because it is portable, easier to handle, lower in cost and does not emit ionizing radiation, especially in developing countries where dual-X-ray absorptiometry devices are less accessible to the general population.[17] QUS employs high frequency sound waves with an emission and receiver probe, to determine bone quality, bone microarchitecture and mechanical parameters by studying speed (Speed of Sound - SOS) and 
attenuation (Broadband Ultrasonic AttenuationBUA) of ultrasonic waves. Sophisticated devices use additional QUS indices like eBMD (Estimated Bone Mineral Density) which can be calculated from the SOS and BUA.18 Longitudinal transmission is more often used, and the preferred, most researched and recognized bone segment measured is the calcaneus as it consists of $95 \%$ trabecular bone and has two lateral surfaces to facilitate the movement of ultrasound through it.

In the classification of low bone density using DXA, T-score with cut-off points of $\leq-1.0$ SD for Osteopenia and $\leq-2.5$ SD for Osteoporosis are used, however, simply applying the DXA cutoffs in QUS measurement can significantly underestimate the true prevalence of Osteoporosis. This was seen in a Korean study (Hologic Sahara QUS device - eBMD) where applicable T-scores for women and men were 2.25 and -1.85 , respectively as compared to $\mathrm{T}$ score of -2.5 , the WHO threshold for Osteoporosis. [19] Another device (Osteometer DTUone) has T score cut offs of -1.45 and -2.10 for BUA and SOS. [20] Reference ranges maybe affected by ethnicity (Caucasian reference BMD range is higher than Asian) and gender. In India and Asia, the light weight Furano CM-200 QUS using SOS parameter is commonly used in Osteoporosis screening camps.

The optimal T-score threshold for Osteoporosis diagnosis in QUS was calculated in eight studies where the value varied between -1 and -2.6 , with a DXA T-score of -0.9 to -3.3 with one study proposing a T-score threshold as low as -3.65 . [21] In most of the studies the QUS T score cut off was either higher (average -2.2+/-0.8) or equal to DXA cut off which correlates with other studies above.

Therefore, the QUS and DXA measurements should not be compared with each other using the same T-score criteria, because of different bone properties measured and different reference populations. A good predictive relationship between hip bone mineral density, as estimated by calcaneal QUS, and direct DXA measurement has been seen, however this correlation decreases for lumbar spine. [22, 23] In patients with Osteoporosis determined by calcaneal QUS or DXA in a Brazilian study, complementing with $\mathrm{X}$-ray was suggested for predicting vertebral fracture. [24]

Based on the population data, investigators have found that -1.455 for the right QUS T score and
-1.48 for the left QUS T score achieved adequate screening parameters to identify Osteoporosis. [25] Cutoff scores produced a sensitivity of $41 \%$ and a specificity of $86.6 \%$ for the right QUS T score and a sensitivity of $51.3 \%$ and a specificity of $83.3 \%$ for the left QUS T score. With a higher QUS T score cut-off of -1.25 , sensitivity was higher at $80.4 \%$ with a specificity of $59.7 \%$ as seen in a study from China. [26] A meta-analysis of 25 studies to assess the accuracy of quantitative ultrasonography compared with DXA in identifying patients with Osteoporosis, various quantitative ultrasonography index parameter cutoffs were used, and the results varied widely in sensitivity and specificity for identifying individuals with a $\mathrm{T}$-score of -2.5 or less on DXA. No quantitative ultrasonography cutoff existed at which sensitivity and specificity were both high. [27]

Using the WHO cutoff value for the definition of osteoporosis based on the $t$-score of $\leq-2.5$ the sensitivity and specificity of DXA were seen to be $88.2 \% 62.5 \%$. [28]

Also, QUS cannot be used for diagnostic classification or staging of Osteoporosis, and it is not clinically useful for monitoring the effects of therapy. [29] Physiologically, calcaneal bone tissue undergoes remodeling much more slowly than central bone (spine and hip). Since bone mineral content changes at different rates in different sites of the body, QUS which evaluates a single site will not be as accurate as a more composite evaluation by DXA therefore early osteoporotic changes may not be captured as effectively by QUS as they would be by DXA scan. [30] Analysis has shown, women diagnosed by QUS are four times more likely to have a fracture in the following year than women screened with DEXA. [31]

\section{CONCLUSION}

Table 2 summarizes the relative advantages and disadvantages of Calcaneal QUS versus Gold standard DXA. For developing countries, Calcaneal QUS can serve as a useful tool for screening but does not have the value of monitoring changes over time. Moreover, different QUS machines have different cut off parameters therefore cannot be compared either with DXA or with each other over time. However Calcaneal QUS, has the advantage of convenience, mass use, low cost, avoiding radiation and easy transport and portability. Its results corroborate with DXA for predicting hip fractures. Traditional WHO DXA cut offs should 
not be applied to Calcaneal QUS, and the same should be based on individual device recommendations. With these points in mind, a
QUS device maybe chosen for screening Osteoporosis risk groups especially in developing countries.

Table2. Comparative advantages and disadvantages of DXA and Calcaneal QUS

\begin{tabular}{|l|l|}
\hline DXA & Calcaneal QUS \\
\hline $\begin{array}{l}\text { Most studied, gold standard and first line screening } \\
\text { method recommended by standard guidelines[30-32] }\end{array}$ & $\begin{array}{l}\text { Suggested as alternative screening method if access } \\
\text { to DXA is limited }\end{array}$ \\
\hline Done at multiple sites - like hip, and spine & Single site - Calcaneum (heel) \\
\hline $\begin{array}{l}\text { Standardized T score cut offs for low bone mass and } \\
\text { Osteoporosis }\end{array}$ & $\begin{array}{l}\text { QUS T score cut offs usually greater than DXA cut } \\
\text { offs and are specific for the particular device. (DXA } \\
\text { cut offs cannot be applied to QUS) }\end{array}$ \\
\hline $\begin{array}{l}\text { Can be used for diagnosis and monitoring response to } \\
\text { therapy }\end{array}$ & Useful only for diagnosis \\
\hline $\begin{array}{l}\text { Can be used for diagnostic classification and disease } \\
\text { staging. }\end{array}$ & $\begin{array}{l}\text { Should not be used for diagnostic classification and } \\
\text { disease staging. }\end{array}$ \\
\hline Can pick up early disease & May not pick up early osteoporotic changes. \\
\hline $\begin{array}{l}\text { Difficult to transport device, requires skill in usage. } \\
\text { Not conducive for camps and high-volume onsite } \\
\text { screening }\end{array}$ & $\begin{array}{l}\text { Convenient and easy to use and transport. } \\
\text { Suitable for camps and high-volume onsite } \\
\text { screening }\end{array}$ \\
\hline High cost & Low cost \\
\hline $\begin{array}{l}\text { Exposure to ionizing radiation - not advised during } \\
\text { pregnancy }\end{array}$ & No exposure to ionizing radiation \\
\hline
\end{tabular}

\section{REFERENCES}

[1] Christodoulou C, Cooper C. What is Osteoporosis? Postgrad Med J 2003;79:133138.

[2] Sozen T, Ozisik L, Basaran NC, An overview and management of Osteoporosis. Eur $\mathbf{J}$ Rheumatol. 2017 Mar; 4(1): 46-56

[3] Kanis JA, Johnell O, Odén A, Dawson A, De LAet C, Jonsson B. Ten year probabilities of osteoporotic fractures according to BMD and diagnosis thresholds. Osteoporosis Int 2001;12:989-95

[4] Johnell O, Kanis J. Epidemiology of Osteoporotic fractures. Osteoporos Int. 2005 Mar;16 Suppl 2:S3-7. Epub 2004 Sep 8.

[5] Cauley JA. Defining Ethnic and Racial Differences in Osteoporosis and Fragility Fractures. Clin Orthop Relat Res. 2011 Jul; 469(7): 1891-1899

[6] Kanis JA, Johansson H, Odén A, Johnell O, De LAet C, Eisman JA, McCloskey EV, Mellström D, Melton LJ III, Pols HA, Reeve J, Silman AJ, Tenenhouse A. A familiy history of fracture and fracture risk: a meta-analysis. Bone 2004;35:1029-37

[7] Kanis JA, De LAet C, Delmas P, Garnero P, Johansson H, Johnell O, Kriger H, McCloskey EV, Mellstrom D, Melton LJ III, Odén A, Pols H, Reeve J, Silman A, tenehouse A. A metaanalysis of previous fracture and fracture risk. Bone 2004 35;375-82

[8] Fitzpatrick LA. Secondary causes of Osteoporosis. May 2002Volume 77, Issue 5, Pages 453-468

[9] Panday K, Gona A and Mary Beth Humphrey MB. Medication-induced Osteoporosis: screening and treatment strategies. Ther Adv Musculoskelet Dis. 2014 Oct; 6(5): 185-202

[10] Law MR, Hackshaw AK. A meta-analysis of cigarette smoking, bone mineral density and risk of hip fracture: recognition of a major effect. BMJ 1997;315:841-6.

[11] Cummings SR, Nevitt MC, Browner WS, et al. Risk factors for hip fracture in white women. $\mathrm{N}$ Engl J Med 1995;332:767-73.

[12] Snow CM, Shaw JM, Matkin CC. Physical activity and risk of Osteoporosis. In: Marcus R, Feldman D, Kelsey J, eds. Osteoporosis. San Diego: Academic Press, 1996: 511-28

[13] Cooper C, Campion G, Melton LJ 3rd. Hip fractures in the elderly: a world-wide projection. Osteoporos Int. 1992 Nov;2(6):285-9

[14] Kadam NS, Chiplonkar SA, Khadilkar AV, Khadilkar VV. Prevalence of Osteoporosis in apparently healthy adults above 40 years of age in Pune City, India. Indian $\mathbf{J}$ Endocr Metab 2018;22:67-7

[15] Dual Energy X ray Absorptiometry - Bone Mineral Densitometry". International Atomic Energy Agency. 2017-08-07. Retrieved 30 May 2019.

[16] Maghraoui AE, Roux C DXA scanning in clinical practice. QJM: An International Journal of Medicine, Volume 101, Issue 8, August 2008, Pages 605-617

[17] Chin KY, Ima-Nirwana S. Calcaneal Quantitative Ultrasound as a Determinant of Bone Health Status: What Properties of Bone Does It Reflect? Int J Med Sci. 2013; 10(12): 1778-1783.

[18] Frost ML, Blake GM, Fogelman I. Can the WHO criteria for diagnosing Osteoporosis be 
applied to calcaneal quantitative ultrasound? Osteoporos Int. 2000;11:321-330

[19] Rhee Y, Lee J, Jung JY, Lee JE, Park SY, Kim YM. et al. Modifications of T-Scores by Quantitative Ultrasonography for the Diagnosis of Osteoporosis in Koreans. J Korean Med Sci. 2009;24:232-6

[20] Frost ML, Blake GM, Fogelman I. Can the WHO Criteria for Diagnosing Osteoporosis be Applied to Calcaneal Quantitative Ultrasound? Osteoporos Int. 2000;11:321-30

[21] Tabor E, Pluskeiwics W. DXA and QUS Comparison-A Systematic Review. J Ultrasound Med 2018; 37:363-369

[22] Collinge $\mathrm{CA}^{1}$, Lebus G, Gardner MJ, Gehrig L. A comparison of quantitative ultrasound of the calcaneus with dual-energy $\mathrm{x}$-ray absorptiometry in hospitalized orthopaedic trauma patients. J Orthop Trauma. 2010 Mar;24(3):176-80. doi: 10.1097/BOT.0b013e3181b8b036

[23] Beerhorst K, Tan J, Yu Tan I, Verschuure P, Aldenkamp AP. Dual-energy X-ray absorptiometry versus quantitative ultrasonography in diagnosing Osteoporosis in patients with refractory epilepsy and chronic antiepileptic drug use. Ther Adv Musculoskelet Dis. 2013 Apr; 5(2): 59-66.

[24] Quiros Roldan E, Brianese N, Raffetti E, Focà E, Pezzoli MC Bonito A et al Comparison between the gold standard DXA with calcaneal quantitative ultrasound based-strategy (QUS) to detect Osteoporosis in an HIV infected cohort. Braz J Infect Dis. 2017 Nov - Dec;21(6):581586.

[25] Steiner B, Dimai HP, Steiner H, Cirar S, Pammer A. Prescreening for Osteoporosis with quantitative ultrasound in postmenopausal white women [published online October 20, 2018]. J Ultrasound Med. doi: 10.1002/jum.14844.
[26] Zha XY1 ${ }^{1}, \mathrm{Hu}$ Y, Pang XN, Chang GL, Li L. Diagnostic value of osteoporosis selfassessment tool for Asians (OSTA) and quantitative bone ultrasound (QUS) in detecting high-risk populations for osteoporosis among elderly Chinese men. J Bone Miner Metab. 2015 Mar;33(2):230-8

[27] Nayak S, Olkin I, Liu H, Grabe M, Gould MK, Allen IE, et al. Meta-analysis: accuracy of quantitative ultrasound for identifying patients with Osteoporosis. Ann Intern Med. 2006; $144: 832-41$

[28] Lewiecki EM, et al. Uses and misuses of quantitative ultrasonography in managing Osteoporosis. Cleve Clin J Med. 2006;73:742752

[29] Humadi A, Alhadithi RH, and Alkudiari SI. Validity of the DEXA diagnosis of involutional osteoporosis in patients with femoral neck fractures. Indian J Orthop. 2010 Jan-Mar; 44(1): 73-78.

[30] NIH Consensus Development Panel on Osteoporosis Prevention, Diagnosis, and Therapy. Osteoporosis prevention, diagnosis, and therapy. JAMA. 2001;285:785-795.

[31] Nelson HD, Helfand M, Woolf SH, Allan JD. Screening for postmenopausal osteoporosis: a review of the evidence for the U.S. Preventive Services Task Force. Ann Intern Med. 2002;137 :529-541

[32] US Preventive Services Task Force. Screening for Osteoporosis to Prevent Fractures US Preventive Services Task Force Recommendation Statement. JAMA. 2018;319(24):2521-2531.

Citation: Varsha Narayanan, Screening for Osteoporosis - Making an Informed Choice of DXA or Calcaneal QUS. ARC Journal of Orthopedics. 2019; 4(1):9-13. doi:dx.doi.org/ 10.20431/2456-0588.0401003.

Copyright: (C) 2019 Authors. This is an open-access article distributed under the terms of the Creative Commons Attribution License, which permits unrestricted use, distribution, and reproduction in any medium, provided the original author and source are credited. 